\title{
The dysplastic naevus
}

\author{
Wolter J Mooi
}

Since the dysplastic naevus (DN) syndrome was first described, ${ }^{12}$ its marker lesion, the $\mathrm{DN}$, has been subject of vehement debate. Major disagreements concerning its macroscopic and microscopic characteristics, its prevalence, its relation to melanoma, its treatment, and indeed its very existence as a separate entity, have continued for two decades. As a result, some have dismissed the entire matter as unsolvable. Some now prefer alternative or related terms such as atypical mole or an eponymic designation, or have included severely dysplastic naevi in a category of melanocytic intrapidermal neoplasia (MIN). ${ }^{34}$ Others have continued to maintain that the dysplastic naevus is a distinct entity, which can and should be distinguished from other naevus types and from melanoma. ${ }^{56}$

Here, an attempt is made to analyse some of the causes of this controversy, with special emphasis on the relation between the predictive value of diagnostic criteria of entities entering the differential diagnosis and the relative prevalence of these entities. Arguments in favour of the continued use of $\mathrm{DN}$ as a separate entity will be provided, and practical guidelines for its diagnosis will be summarised.

\section{Historical background}

In the late 1970 s, reports emerged of a familial syndrome characterised by multiple and abnormal naevi, associated with a very high risk of melanoma. ${ }^{12}$ In families with the "dysplastic naevus syndrome", the clinical phenotype and melanoma risk were found to segregate with an autosomal dominant pattern of inheritance, suggesting the presence of a single causative gene.

The abnormal naevi, which were initially considered diagnostic of this familial dysplastic naevus syndrome, or FAMMM (familial atypical multiple mole melanoma ${ }^{7}$ syndrome, were soon also recognised in patients with a similar clinical phenotype of multiple abnormal moles, often in association with melanoma, but with a negative family history. ${ }^{8}$ Controversy regarding their significance as melanoma risk markers arose when they were also identified as solitary lesions in otherwise unremarkable individuals; indeed, solitary atypical naevi were noted in $2-9 \%$ or even more of the general population. ${ }^{9-13}$ Indeed, to some degree, the clinical and histological features of $\mathrm{DN}$ were found to be related to endogenous (endocrine) or exogenous (solar irradiation) stimuli, ${ }^{14}{ }^{15}$ blurring the distinction between $\mathrm{DN}$ and other common acquired naevi.

Unfortunately, different authors applied different criteria for the clinical and histological diagnosis of DN. These differences preclude a detailed comparison of data from different series and a conclusion with respect to the apparent discrepancies between series. Several attempts at consensus met with only partial success, as is apparent from the differences in diagnostic criteria that continue to be used.

\section{Usefulness of the terms dysplasia and DN}

The term dysplastic naevus has been repeatedly criticised. ${ }^{16}{ }^{17}$ In pathology, the term dysplasia is used in very different ways-for example, dysplastic goiter, dysplasia of the uterine cervix, bronchopulmonary dysplasia. Therefore, is was argued, the term would be too ambiguous to be used at all. However, it should be borne in mind that in all language, including scientific language, words have different meanings in different contexts. The context defines its meaning in the individual instance. Indeed, the word mole may refer to an animal or a cutaneous pigmented lesion. The term dysplasia in the context of naevi indicates a combination of cellular and architectural irregularities, described in detail below, and associated to varying degrees (depending primarily on clinical context) with increased melanoma risk.

Nonetheless, some dermatologists and pathologists now favour alternative designations such as atypical mole. However, the words atypical and mole are at least as varied in their meaning as is the word dysplastic. The term melanocytic intraepidermal neoplasia (MIN), which lumps together severely dysplastic naevi and in situ melanoma, ${ }^{34}$ has the advantage of abolishing the problem ridden histological distinction between DN and in situ melanoma, a distinction that has no apparent clinical relevance, but has other disadvantages. Very severely dysplastic DN are compound rather than intraepidermal, and the term neoplasia would also be applicable to other naevus types. In my opinion, the term $\mathrm{DN}$ remains the best choice. 


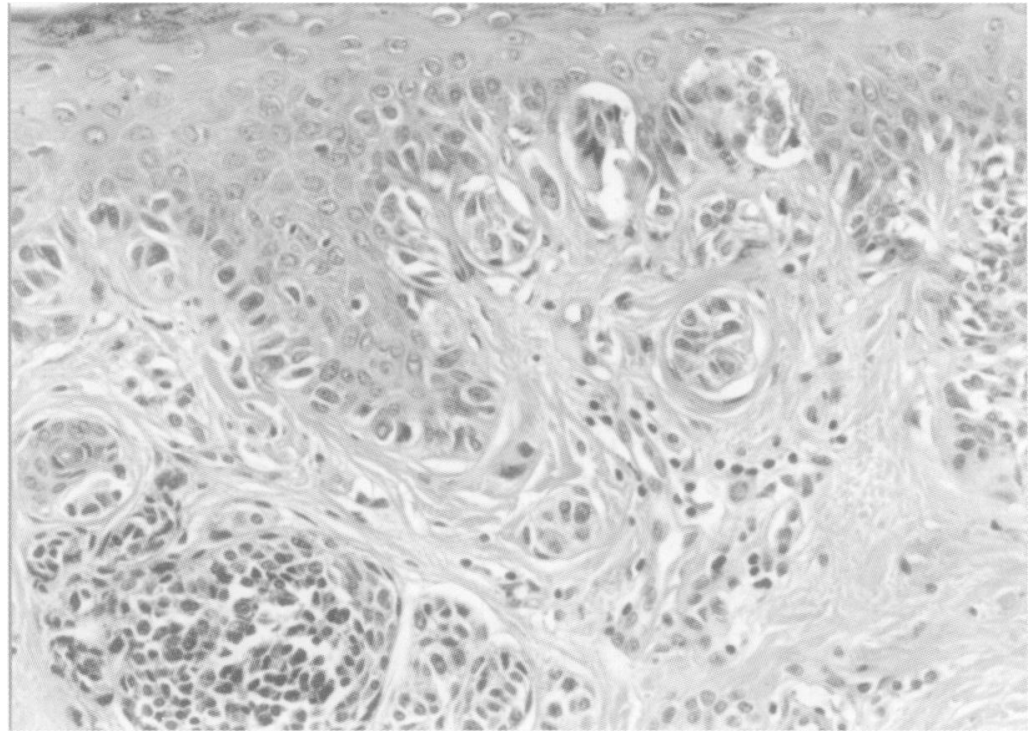

Figure 1 Dysplastic compound naevus. Irregular distribution melanocytes arranged in nests and lentiginous patterns along the dermoepidermal junction. Irregular rete ridges, in part surrounded by lamellar sclerosis. Slightly irregular distribution of intradermal melanocytic nests and smaller cell groups.

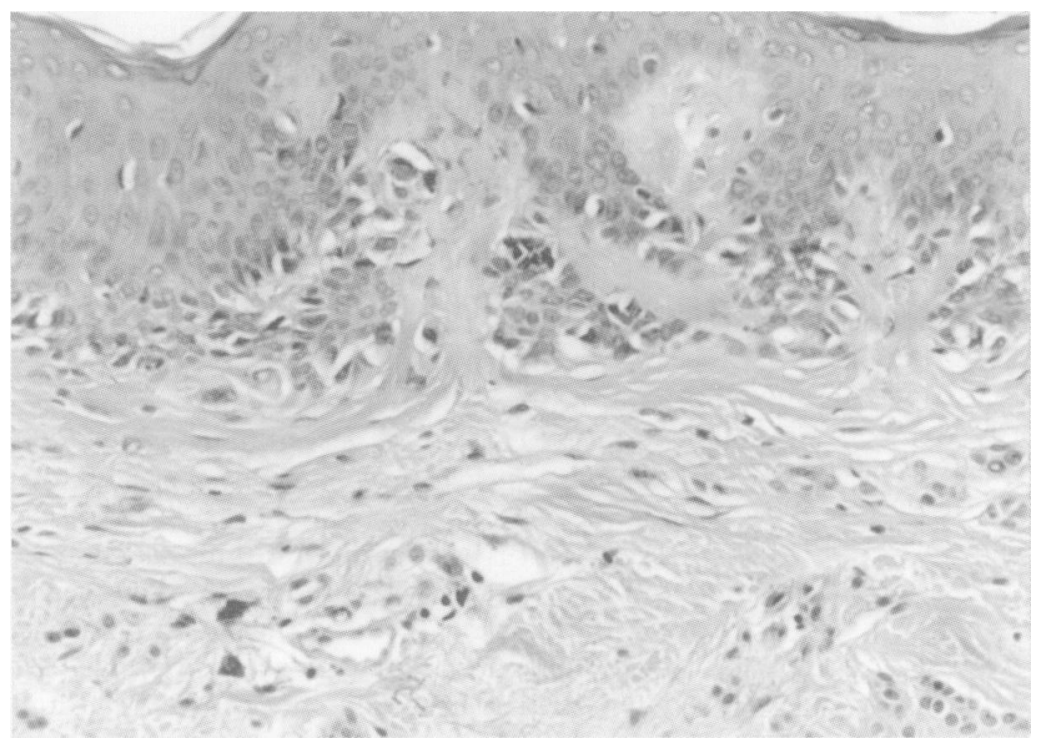

Figure 2 Dysplastic compound naevus. Irregular rete ridges, surrounded by pronounced lamellar sclerosis. should not be made when the lesion is smaller than $5 \mathrm{~mm}$ in diameter clinically ${ }^{18}$ or $4 \mathrm{~mm}$ across on the slide. This is because a large number of small naevi, at an early stage of their development when still only a few millimetres in diameter, exhibit some or many of the histological features of $\mathrm{DN}$, especially irregular nesting with occasional rete ridge bridging, as well as lamellar subepidermal sclerosis. It is the combination of larger size and the histology that characterises DN.

\section{ARCHITECTURAL FEATURES}

Most DN are compound, possessing a junctional and an intradermal component. A small minority of DN are entirely junctional. No intradermal $\mathrm{DN}$ is recognised. Compound dysplastic naevi often have a slightly raised centre and a flat periphery, which consists of junctional lateral spread of the proliferation, associated with irregular rete ridge elongation and subepidermal sclerosis (fig 1), often consisting of stacks of slightly refractile collagen fibres (lamellar fibrosis; fig 2).

The junctional component generally consists of nests as well as solitary cells arranged in a lentiginous pattern. The nests are irregularly sized and shaped, and often have a horizontal orientation bridging adjacent epidermal rete ridges. The lentiginous proliferations of melanocytes are similarly irregularly distributed (fig 1). The junctional component is highly cellular, in areas replacing the large majority of basal epidermal keratinocytes. Both nests and lentiginous proliferations usually extend somewhat along the epithelium of cutaneous adnexae. Mitotic figures are rare. Ascent of solitary melanocytes so that these cells reach the granular layer is also absent or rare in DN. If present, the ascending cells are small, with compact, dark nuclei, and little cytoplasm.

The dermal component of dysplastic compound naevi is located at the centre, so that the lesion is symmetrical. Generally, well defined nests and strands of melanocytes predominate in the subepidermal part, which exhibits distinct sclerotic changes. Deeper parts of the naevus consist of ill defined aggregates or, less commonly, more compact small groups of cells. Larger, compact, spherical intradermal nodules are absent-their presence should raise a strong suspicion of (vertical growth phase) melanoma. Melanocytes at the base of the lesion are usually small but may be pigmented. Generally, the intradermal component of $\mathrm{DN}$ is not very extensive.

The dysplastic naevus exhibits a characteristic host response, consisting of irregular rete ridge elongation, together with subepidermal sclerosis, which takes the shape of dense, refractile stacks of collagen fibres around rete ridges and along capillaries of dermal papillae. Proliferation of dermal capillaries and a perivascular lymphohistiocytic inflammatory infiltrate are invariably present.

Importantly, the architectural and cellular features of different parts of the naevus are similar - at any level of the lesion, the cell type is similar throughout. In this, the DN resembles most other naevus types, and is distinct
The histological diagnosis of $\mathrm{DN}$ is based on a combination of cytological and architectural features, including a characteristic host response. It is advised that the diagnosis of DN 


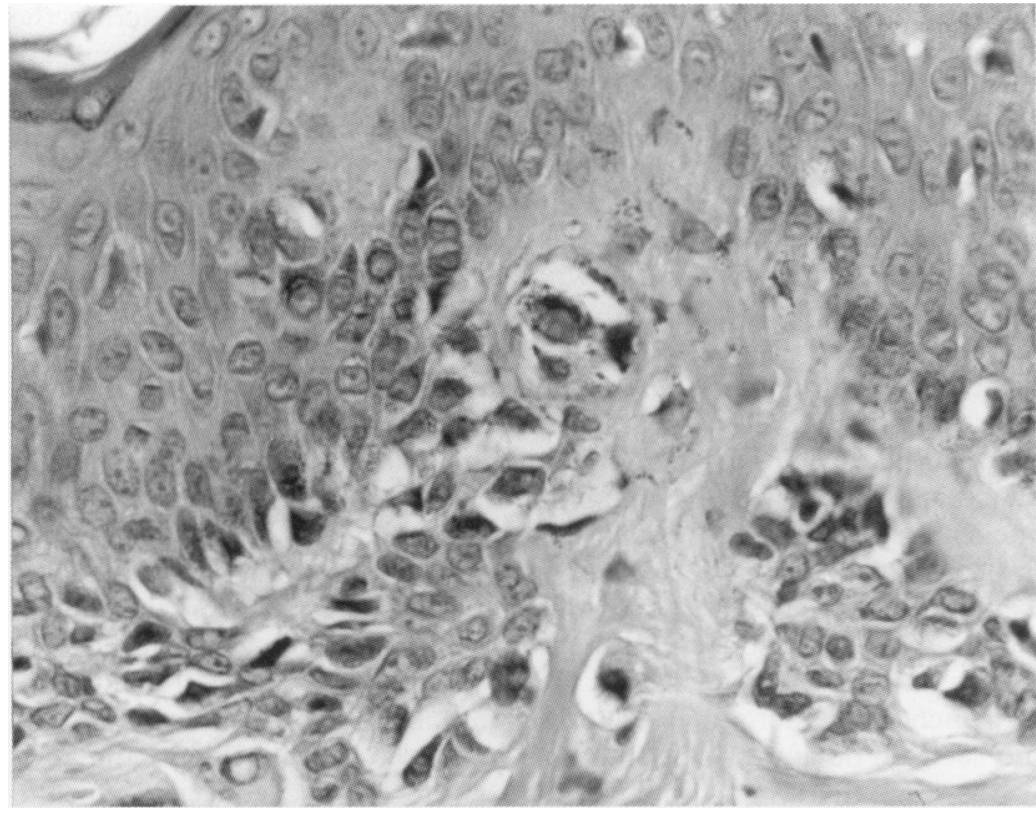

Figure 3 Dysplastic compound naevus (detail of fig 2). Note irregular distribution of junctional melanocytes, associated with distinct anisonucleosis.

from most melanomas, which exhibit more variation in architecture and cellular features.

CYTOLOGICAL FEATURES

The melanocytes of DN exhibit nuclear atypia, especially nuclear pleomorphism and anisochromatism, most obvious at the dermoepidermal junction and in the subepidermal region (fig 3). Such nuclear atypia is a prerequisite for a positive diagnosis of $\mathrm{DN} .{ }^{19}$ It is the variability in size, shape, and staining intensity of the nuclei, rather than their absolute size, that is most characteristic of DN. Nuclei of melanocytes in Spitz naevi, pigmented spindle cell naevi, blue naevi, and deep penetrating naevi may be large, but in these latter naevus types, the variability of nuclear features is less striking than in a DN. In contrast to most melanomas, the nuclear pleomorphism is similar in different areas of the lesion. In melanoma, there is often a difference in nuclear features between different nests or aggregates.

In my experience, the presence of dusty pigment in junctional melanocytes is of little practical use in the differential diagnosis, as it may also be present in melanoma as well as in some common acquired naevi, Spitz naevi, deep penetrating naevi, and balloon cell naevi. Intradermal mitotic figures are absent or exceedingly rare. Their presence should raise a suspicion of melanoma.

None of the histological features of DN that have been put forward is diagnostic by itself, ${ }^{20}$ it is a combination of features, rather than any single feature in isolation, that sets apart these naevi. If used in this way, there is a fair correlation between the histological and clinical diagnosis of $\mathrm{DN}^{21}$

As each of the features relevant to the diagnosis of $\mathrm{DN}$ can be present to various degrees, and in various combinations, classification problems of borderline cases are unavoidable. This is especially problematic with respect to the differential diagnosis between common acquired naevus and DN.
Obviously, the combination of distinct cytological and architectural atypical features in a naevus of an affected familial DN syndrome patient does not provide major diagnostic difficulties. However, such cases are rare in comparison to the very large number of naevi with only some of these features, occurring in otherwise unremarkable individuals. It is clear that a restrictive diagnostic approach to DN will exclude the large majority of these latter lesions.

The grading of dysplasia in $\mathrm{DN}$ is advocated by some workers; however, since it results in significant intraobserver and interobserver variability ${ }^{22}{ }^{23}$ I have discontinued grading $\mathrm{DN}$.

\section{Relative prevalence of entities $v$} predictive value of diagnostic criteria An important consideration, often overlooked in discussions on the practical value of diagnostic criteria, is the profound impact of the relative prevalence of two entities requiring differentiation, on the predictive value of a given criterion used to differentiate the two. ${ }^{24}$ In other words, a feature, or a combination of features, needs to have a very high specificity if it is to be of use in the positive identification of a rare entity.

This is probably of central relevance to the controversy on dysplastic naevi. Naevi submitted for histology constitute a very small proportion of the naevi in the general population. The reason for removal is usually either cosmetic or a suspicion of melanoma. Slides referred for expert opinion reflect a substantial bias, the numbers of problem cases, including $\mathrm{DN}$, is much higher in such series. Significantly, published series used for the study of interobserver variability in the diagnosis of $\mathrm{DN}$ have included relatively large numbers of $\mathrm{DN},{ }^{1422} 25{ }^{26}$ which contrasts with the material received in general diagnostic pathology laboratories where non-dysplastic naevi greatly outnumber DN. In these latter diagnostic pathology laboratories, a problem of insufficient specificity of diagnostic criteria for $\mathrm{DN}$ is encountered; this problem is masked to a considerable extent in studies based on selected material in which DN are greatly overrepresented. To avoid this problem, as far as possible a conservative approach in the diagnosis of $\mathrm{DN}$ is advised: only those naevi $6 \mathrm{~mm}$ or larger in diameter and meeting the combination of the cytological and architectural abnormalities summarised above should be designated DN.

\section{Dysplastic naevus $v$ early melanoma}

The distinction between DN and melanoma is of greater importance clinically than between $\mathrm{DN}$ and common acquired naevi. A number of negative findings is of central importance in the distinction of DN from small melanomas. In $\mathrm{DN}$, there is no pagetoid spread of atypical melanocytes at all levels of the epidermis, across most or all of the lesion. Moreover, intradermal mitoses are absent, unless a brisk inflammatory infiltrate permeates the dermal part of the lesion. Atypical mitotic figures are invariably absent. Distinct differences in pres- 
ence, degree or aspect of inflammation and fibrosis between different areas of the lesion are lacking in DN.

The malignant potential of many thin, presumably early, melanomas as they are diagnosed today is far from clear. The question arises: are these so called early melanomas really melanomas-that is, fully malignant tumours that were discovered in time, or do they only resemble melanoma, clinically and histologically, but need further steps before the potential to invade and metastasise is acquired? Follow up data of the large material of Elder $e t$ $a l^{27}$ and Clark et $a l^{28}$ indicate that radial growth phase melanomas never metastasise. Although independent confirmation of their conclusions is necessary before the acceptance of radial and vertical growth phase melanoma as diagnostic concepts, their findings raise an interesting point: if there is a phase in which a melanoma never metastasizes, it would seem to be appropriate to conclude that at this stage the lesion may be a precursor lesion of malignancy, but has not yet acquired a fully malignant phenotype, and therefore is not really an early melanoma. Further studies on thin metastasising melanomas are essential to identify small melanomas with a greater degree of precision, and to attain a greater degree of confidence in excluding the diagnosis of melanoma in thin worrisome lesions. The outcome of such ongoing work will no doubt contribute significantly to the distinction between $\mathrm{DN}$ and melanoma.

\section{The practical role of the pathologist in the diagnosis of dysplastic naevi}

Early reports on DN seemed to indicate that the histopathologist would be able to identify with considerable reliability a naevus type that, regardless of clinical context, would constitute a marker of clinically significant melanoma risk. Clearly, this is not the case. It is the clinical evaluation (numbers, distribution and macroscopic appearance of the patient's naevi, and family history) that is the best basis for the diagnosis and clinical management of the $\mathrm{DN}$ syndrome. It should, however, be borne in mind that the clinical reproducibility of $\mathrm{DN}$, as shown by recent interobserver variability studies based on photographs of single naevi, is limited. ${ }^{29} 30$ The primary task of the histopathologist, with respect to $\mathrm{DN}$, is to rule out melanoma. A patient with the clinical phenotype of the DN syndrome should be carefully monitored and excessive exposure to sunlight should be avoided. Prophylactic removal of all $\mathrm{DN}$ is a futile exercise, $\mathrm{DN}$ continue to arise, change in appearance, and disappear throughout adult life. ${ }^{31}{ }^{32} \mathrm{~A}$ change in size or appearance of a previously stable naevus raises a suspicion of malignant transformation and should lead to excision of the lesion. The practical relevant question in such an instance is not, is the naevus dysplastic? but rather, is the lesion a melanoma?

If the pathologist diagnoses a $\mathrm{DN}$, it is wise to add a note in the report indicating that this finding per se does not imply that the patient has a significant risk for melanoma, but that a proper clinical evaluation of the numbers, dis- tribution, and appearance of naevi across the entire skin is advised. If the clinical findings are within normal limits, the diagnosis apparently has no obvious further consequences.

\section{Conclusions}

From the above, a number of conclusions can be drawn:

(1) The clinical diagnosis of familial DN syndrome is based primarily on the clinical assessment of number, distribution, and appearance of naevi on the entire skin, in combination with family and personal history.

(2) The histological investigation of a single naevus does not effectively identify $\mathrm{DN}$ syndrome patients. The main objective of the histological investigation of a naevus in the clinical setting of DN syndrome is to rule out melanoma.

(3) Substantial controversy in the histopathological literature concerning the predictive value of criteria or sets of criteria for the diagnosis of $\mathrm{DN}$ is probably related to large differences in relative prevalence of entities in series studied or materials received in the diagnostic pathology laboratory.

(4) A restrictive approach in the histological diagnosis of $\mathrm{DN}$ is advised, as it results in a better correlation with personal or family history of melanoma.

In recent years, genetic studies of familial DN syndrome kindred have resulted in the identification of at least two loci, on chromosomes 1 and $9,^{33}$ associated with the $\mathrm{DN}$ syndrome phenotype. Apparently, there is genotypic heterogeneity in this syndrome. Future studies of the genetics of DN syndrome may provide clues at the DNA level, which may hopefully constitute an additional marker in the pathological diagnosis of sporadic DN.

1 Frichot BC, Lynch HT, Guirgis HA, Harris RE, Lynch JF. A new cutaneous phenotype in familial malignant melanoma. Lancet 1977:864-5.

2 Clark WH, Reimer RR, Greene $M$, Ainsworth AM Mastrangelo MJ. Origin of familial malignant melanomas from heritable melanocytic lesions. "The $\mathrm{B}-\mathrm{K}$ mole syndrome". Arch Dermatol 1978;114:732-8.

3 Cook MG, Clarke TJ, Humphreys S, Fletcher A, McLaren KM, Smith NP, et al. The evaluation of diagnostic and prognostic criteria and the terminology of thin cutaneous prognostic criteria and the terminology of thin cutaneous malignant melanoma by the CRC Melan
Panel. Histopathology 1996;28:497-512,

4 Cook MG, Clarke TJ, Humphreys S, Fletcher A, McLaren KM, Smith NP. CRC Melanoma Panel. A nationwide survey of observer variation in the diagnosis of thin cutaneous malignant melanoma including the MIN terminology. Clin Pathol 1997;50:202-5.

5 Cook MG, Fallowfield ME. Dysplastic naevi-an alternative view. Histopathology 1990;16:29-35.

6 Cochran AJ, Bailly C, Paul E, Remotti F. Melanocytic tumors. A guide to diagnosis. Philadelphia: Lippincott-Raven, 1997: A guide 110 .

7 Lynch HT, Frichot BC, Lynch JF. Familial atypical multiple mole melanoma syndrome. 7 Med Gen 1978;15:352-6.

8 Elder DE, Goldman LI, Goldman SC, Greene MH, Clark WH. Dysplastic nevus syndrome: a phenotypic association of sporadic cutaneous melanoma. Cancer 1980;46:178794.

9 Rhodes AR, Sober AJ, Mihm MC, Fitzpatrick TB. Possible risk factors for primary cutaneous melanoma [abstract] Clin Res 1980;28:252A

10 Sheiber A, Milton GW, McCarthy MH, Shaw H. Clinica features, prognosis and incidence of multiple primary cutaneous malignant melanoma. Aust $N Z \mathcal{Z}$ Surg 1981;51:386.

11 Crutcher WA, Sagebiel RW. Prevalence of dysplastic naevi in a community practice [letter]. Lancet 1984;i:729.

12 Greene MH, Elder DE, Tucker MA, Guerry D. The dysplastic nevus syndrome. In: Veronesi $U$, Cascinelli $N$, Santinami M, eds. Cutaneous melanoma. Status of knowledge and future perspective. London: Academic Press, 1987:279318.

13 Cook KR, Spears GFS, Elder DE, Greene MH. Dysplastic nevi in a population-based survey. Cancer 1989;63:1240-4 
14 Piepkorn MW, Barnhill RL, Cannon-Albright LA, Elder $\mathrm{DE}$, Goldgar DE, Lewis CM, et al. A multiobserver, population-based analysis of histologic dysplasia in melanocytic nevi. $\mathcal{F}$ Am Acad Dermatol 1994;30:707-14.

15 Armstrong BK, Heenan PJ, Caruso V, Glancy RJ, Holman CDJ. Seasonal variation in the junctional component

16 Ackerman AB. What naevus is dysplastic, a syndrome and the commonest precursor of malignant melanoma? A riddle and an answer. Histopathology 1988;13:241-56.

17 Ackerman AB, Mihara I. Dysplasia, dysplastic melanocytes, dysplastic nevi, the dysplastic nevus syndrome, and the relation between dysplastic nevi and malignant melanomas. relation between dysplastic nev

18 Elder DE, MacKie RM. Dysplastic melanocytic nevi. Their nature and significance. In: Cascinelli N, Santinami $M$ Veronesi U, eds. Cutaneous melanoma, biology and management. Milan: Masson, 1990:93-104.

19 Barnhill RL, Roush GC, Duray PH. Correlation of histologic architectural and cytoplasmic features with nuclear atypia in atypical (dysplastic) nevomelanocytic nevi. Hum Pathol 1990;21:51-8.

20 Hastrup N, Hou-Jensen K. Melanocytic lesions in a private pathology practice. Comparison of histologic features in different tumor types with particular reference to dysplastic nevi. APMIS 1993;101:845-50.

21 Black WC, Hunt, WC. Histologic correlations with the clinical diagnosis of dysplastic nevus. Am $\mathscr{f}$ Surg Pathol 1990;14:44-52.

22 De Wit PE, Van 't Hof-Grootenboer B, Ruiter DJ, Bondi R, Brocker EB, Cesarini JP, et al. Validity of the histopathological criteria used for diagnosing dysplastic naevi. An interobserver study by the pathology subgroup of the EORTC Malignant Melanoma Cooperative Group. Eur $\mathcal{F}$ Cancer 1993;29A:831-9.

23 Duncan LM, Berwick M, Bruijn JA, Byers HR, Mihm MC Barnhill RL. Histopathologic recognition and grading of dysplastic melanocytic nevi: an interobserver agreement dysplastic melanocytic nevi: an interobserver
study. $\mathcal{F}$ Invest Dermatol 1993;100:318S-21S.
24 Vecchio TJ. Predictive value of a single diagnostic test in unselected populations. N Engl f Med 1966;274:1171-3.

25 Steijlen PM, Bergman W, Hermans J, Scheffer E, Van Vloten WA, Ruiter DJ. The efficacy of histopathological criteria required for diagnosing dysplastic naevi. Histopathology 1988;12:289-300.

26 Duray PH, DerSimonian R, Barnhill R, Stenn K, Ernstoff MS, Krikwood JM. An analysis of interobserver recognition of the histopathologic features of dysplastic nevi from a mixed group of nevomelanocytic lesions. $7 \mathrm{Am} \mathrm{Acad} \mathrm{Der-}$ matol 1992;27:741-9.

27 Elder DE, Guerry D IV, Epstein MN. Invasive malignant melanomas lacking competence for metastasis. $\mathrm{Am} \mathcal{f}$ Dermatopathol 1984;6:55S-62S.

28 Clark WH, Elder DE, Guerry D IV, et al. Model predicting survival in stage I melanoma based on tumor progression. f Natl Cancer Inst 1989;81:1893-904.

29 Hartge P, Holly EA, Halpern A, Sagebiel R, Guerry D, Elder D, et al. Recognition and classification of clinically dysplastic nevi from photographs: a study of interobserve variation. Cancer Epidemiol Biomarkers Prev 1995;4:37-40.

30 Meyer LJ, Piepkorn M, Goldgar DE, Lewis CM, CannonAlbright LA, Zone JJ, et al. Interobserver concordance in discriminating clinical atypia of melanocytic nevi, and correlations with histologic atypia. $\mathcal{F}$ Am Acad Dermatol 1996; 34:618-25.

31 Halpern AC, Guerry D 4th, Elder DE, Trock B, Synnestvedt M, Humphreys T. Natural history of dysplastic nevi. 7 Am Acad Dermatol 1993;29:51-7.

32 Barnes LM, Nordlund JJ The natural history of dysplastic nevi. Arch Dermatol 1987;123:1059-61.

33 Bergman W, Gruis NA, Sandkuijl LA, Frants RR. Genetics of seven Dutch familial atypical multiple mole melanoma syndrome families: a review of linkage results including chromosomes 1 and 9. F Invest Dermatol 1994;103:122S$5 S$. 